\title{
AS CARACTERÍSTICAS DEFINIDORAS DAS ACELERADORAS E SUAS DIFERENÇAS PARA OUTRAS ORGANIZAÇÕES FILANTRÓPICAS
}

\author{
Patrick Kahlil Travers ${ }^{1}$, Clarissa Stefani Teixeira ${ }^{2}$ \\ ${ }^{1,2}$ Universidade Federal de Santa Catarina \\ ${ }^{1}$ metricpatrickegmail.com \\ ${ }^{2}$ clastefanilgmail.com
}

\section{Resumo}

As aceleradoras surgiram na última década. Por serem um fenômeno relativamente recente, as pesquisas também são novas. Todavia, há alguns pesquisadores, notadamente Susan Cohen e Yael V. Hochberg, que conseguiram estabelecer uma base a respeito das definições e nuanças das aceleradoras. Este artigo propõe exibir os principais temas que esses autores discutem, mostrando as tipologias e características das aceleradoras, como também suas diferenças para outras instituições filantrópicas (incubadoras e investidores anjo).

Palavras Chave: Startup, accelerator. Startup accelerator.

\section{THE DEFINITIVE CHARACTERISTICS OF THROTTLE ACCELERATORS AND THEIR DIFFERENCES FOR OTHER PHILANTHROPIC ORGANIZATIONS}

\begin{abstract}
The first accelerators appeared in the last decade. Since they're a relatively recent phenomenon, the research on them is also quite new. However, there are some researchers, notably Susan Cohen and Yael V. Hochberg, that have been able to establish a good framework when it comes to the definition and nuances of accelerators. This article proposes to exhibit the main themes these authors discuss, showing the different types and characteristics of accelerators, as well as their differences to other philanthropic organizations (incubators and angel investors).
\end{abstract}

Keywords: Startup, accelerator.

\section{Introdução}

As aceleradoras são organizações que auxiliam as empresas startups, que normalmente passam por várias dificuldades no seu começo, sendo elas desde falta de financiamento até problemas jurídicos. Há outras organizações que também agem nessa mesma proposta, como incubadoras e investidores anjo, porém elas possuem métodos diferentes para alcançar esse fim.

Outras organizações filantrópicas notáveis são os venture capitalists (VC), os espaços co-creation, as organizações de mentoria, entre outros [BLIEMEL et al. 2016]. Nota-se que de todos esses grupos, os investidores anjos são os que possuem objetivo mais parecida com a das aceleradoras. A maioria das organizações não-governamentais possuem o interesse em obter uma ação acionária ao investir em uma startup e, dessa forma, é benéfico a eles 
prestarem auxílio às startups neste momento inicial da criação, pois esta etapa é a mais instável da empresa e consequentemente quando a maioria delas acabam falindo.

O tempo e o dinheiro que estas instituições filantrópicas investem nas startups varia bastante. As aceleradoras nos Estados Unidos, por exemplo, oferecem um programa que dura em média 3 meses e investem \$26,000 para uma participação acionária de tipicamente 5-7\% [HOCHBERG 2015], enquanto que as incubadoras normalmente prestam auxílio de 1 a 5 anos e sem a tomada de uma ação acionária [COHEN e HOCHBERG 2014].

Nota-se, porém, que ainda há dificuldade com a semântica de alguns dos termos usados neste ecossistema, seja por serem conceitos que surgiram a pouco tempo ou por serem empregados erroneamente por alguns empresários. Unicórnios, aceleradoras e startups são exemplos disso. A academia, entretanto, vem ao longo dos anos melhorando as definições dessas organizações, notadamente a respeito das aceleradoras. Assim, o presente estudo busca definir o que é uma aceleradora, saber suas características e como ela difere de investidores anjo e incubadoras.

\section{Metodologia}

Este artigo classifica-se como pesquisa bibliográfica [CERVO e BERVIAN 1983, p.55], ou seja, é a explicação de um problema a partir de referenciais teóricos publicados em documentos, de forma que busca conhecer e analisar as contribuições culturais ou científicas existentes sobre um determinado assunto, tema ou problema.

A pesquisa foi elaborada a partir de artigos internacionais, predominantemente dos Estados Unidos. Utilizou-se as bases de dado ScienceDirect e MITLibraries por recuperarem a produção científica mundial e por serem interdisciplinares. $\mathrm{O}$ acesso foi realizado no dia 11 de julho de 2017 A palavra-chave usada foi "startup accelerator", pois ao usar somente "accelerator", apareciam majoritariamente artigos que discutiam sobre aceleradoras de partículas.

No ScienceDirect, obteve-se 1512 resultados ao utilizar a palavra-chave "startup accelerators". Enquanto que no MITLibraries, apareceram 28834 resultados, porém, usou-se o filtro para mostrar somente os assuntos (em inglês): Science; United States; business; business periodicals; entrepreneurship; Science bibliography periodicals industries; United States Publication board bibliography periodicals; technological innovations; new business enterprises; research; business enterprises. Ao ser aplicado o filtro, apareceram 1055 resultados. Em seguida, procurou-se artigos que descrevessem as características fundamentais de aceleradoras, como também suas diferenças para outras instituições filantrópicas. Dos dois bancos de dados, analisou-se no final 14 artigos.

\section{Startups}

O consenso geral da definição de startups é que elas são empresas escaláveis e de alto potencial de crescimento graças a sua base de inovação (disruptiva). Porém, o debate sobre a definição concreta do rótulo "startup" ainda continua. Provavelmente, qualquer negócio novo pode tornar-se um startup, por isso, uma definição exata para startup é difícil de se obter [BLIEMEL et al. 2016].

Alguns exemplos de empresas grandes que eram startups são reddit, dropbox, AirBnB, Scribd e Heroku, que vieram da aceleradora Y Combinator [MILLER e BOUND 2011]. Notase que essas empresas são websites ou softwares que oferecem algum serviço ou oferta aos seus clientes. Elas diferem-se de empresas tradicionais (ex.: Toyota, Walmart) no sentido de que elas têm um menor custo para se sustentarem e um alto potencial de crescimento por serem baseados na internet. 
Existem organizações e indivíduos que auxiliam startups por vários motivos. A seguir, são indicadas as características, definições e motivações das aceleradoras que atualmente dão suporte para o estabelecimento e crescimento das startups.

\section{Aceleradoras}

Aceleradoras são organizações que ajudam startups a definir e construir seus produtos iniciais, identificar clientes promissores para elas, e segurar recursos, tais como funcionários e capital. As aceleradoras geralmente fornecem uma pequena quantidade de capital semente e um espaço de trabalho em troca de uma participação acionária na startup. Nos Estados Unidos, isso equivale a um investimento inicial em média de $\$ 26,000$, variando de $\$ 0$ à $\$ 150,000$, com uma participação acionária de tipicamente 5-7\% [HOCHBERG 2015]. Elas também oferecem oportunidades de networking e mentoria com empreendedores bemsucedidos, graduandos do programa, venture capitalists, investidores anjo ou até mesmo empresas executivas. Finalmente, a maioria dos programas termina com um grande evento, o "demo day", onde as startups se apresentam em frente a uma grande plateia de investidores experientes [COHEN 2013] [HOCHBERG 2015]. O quadro 1 mostra os investimentos de algumas aceleradoras populares.

Quadro 1 - investimentos de aceleradoras.

\begin{tabular}{|l|c|c|c|c|}
\hline \multicolumn{1}{|c|}{ Aceleradora } & $\begin{array}{c}\text { Participação } \\
\text { acionária }\end{array}$ & $\begin{array}{c}\text { Quantidade de capital } \\
\text { semente }\end{array}$ & $\begin{array}{c}\text { Outros } \\
\text { investimentos }\end{array}$ & $\begin{array}{c}\text { Acesso a VCs } \\
\text { e anjos }\end{array}$ \\
\hline Capital Factory & $5 \%$ & $\$ 20,000$ e adicionais & - & Sim \\
\hline $\begin{array}{l}\text { LaunchBox } \\
\text { Industry }\end{array}$ & Até $65 \%$ & $\$ 20,000$ & Sim \\
\hline Start@Spark & - & Empréstimo até \$250,000 & $\begin{array}{c}\text { Direito a investir } \\
\text { na próxima } \\
\text { rodada }\end{array}$ & Sim \\
\hline TechStars & $5-6 \%$ & $\begin{array}{c}\$ 6,000 \text { (por fundador) } \\
\text { máx. \$18,000 }\end{array}$ & $\begin{array}{c}\text { Espaço de } \\
\text { trabalho }\end{array}$ & Sim \\
\hline Y Combinators & $\begin{array}{c}2-10 \%, \text { em } \\
\text { média 6-7\% }\end{array}$ & $\begin{array}{c}\$ 17,000(2 \text { fundadores }) \\
\$ 20,000(3 \text { fundadores) }\end{array}$ & $\begin{array}{c}\text { Espaço de } \\
\text { trabalho }\end{array}$ & Sim \\
\hline
\end{tabular}

Fonte: Traduzido do Hoffman e Radojevich, 2012.

Antecedentes de aceleradoras datam do início dos anos 2000 (quando a CMGI, uma empresa VC, comprou equidade de um grande número de empresas startups da Internet), mas o modelo moderno e canônico de programas de aceleração foi estabelecido pelo Y Combinator, fundado em 2005 [KIM e WAGMAN 2014]. O IdeaLab, fundado em 1996 por Bill Gross e seus colegas, é considerado por alguns como a primeira aceleradora, embora ele não leve empresas em coortes ou "turmas" como as atuais [MILLER e BOUND 2011].

$\mathrm{Na}$ prática, as aceleradoras são uma combinação de distintos serviços/funções que antes eram caros para um empreendedor encontrar e obter individualmente. A abordagem da aceleradora foi amplamente adotada por grupos privados e públicos, por corporações e por esforços governamentais [HOCHBERG 2015].

\subsection{Definiçãa de aceleradora}

Um dos problemas que se encontra ao tentar analisar o impacto que as aceleradoras têm no mercado é contar quantas realmente existem. Esta dificuldade surge pela (suposta) falta de uma definição concreta para as aceleradoras. Contudo, há autores que já propuseram algumas definições, como Miller e Bound [2011] e Barrehag et al. [2012], indicando que as 
aceleradoras são de uma maneira mais ampla pautadas em cinco características principais, as quais serão apresentadas nos subtópicos subsequentes.

Um processo de inscrição aberto e altamente competitivo: $O$ processo de seleção geralmente começa com o preenchimento de um questionário online. Se um pedido for considerado interessante pela aceleradora, os candidatos serão convocados para uma entrevista. Muitos dos programas têm uma taxa de aceitação muito baixa, tanto que as aceleradoras mais conhecidas aceitam menos que $1 \%$ dos candidatos. Logo, é importante que a seleção seja feita por uma pessoa qualificada e experiente que possa avaliar os candidatos e seus respectivos potenciais.

Prestação de investimentos pré-semente, normalmente em troca de equidade: As aceleradoras investem uma quantidade pequena nas startups durante o programa, normalmente em troca de uma ação acionária na empresa. Este investimento é destinado a cobrir suas despesas durante o programa, sendo este, na maioria das vezes, financiado por investidores externos.

Foco em pequenas equipes e não em indivíduos: A maioria das aceleradoras não aceita startups com apenas um fundador, a não ser para situações excepcionais. Como diz Y Combinator: "Uma startup é muito trabalho para somente uma pessoa". Assim, as aceleradoras preferem trabalhar com pequenas equipes, porém desde que sejam até quatro pessoas, pois mais do que isso aumenta os custos para a organização.

Suporte em tempo limitado, incluindo eventos programados e tutoria intensiva: A maioria das startups que entram numa aceleradora trabalham com produtos relacionados à web, dessa forma, as iterações e o desenvolvimento de produtos podem ser feitos rapidamente. Os programas geralmente duram cerca de três meses e acredita-se que isso crie uma sensação de urgência a qual incentiva um trabalho intenso e um progresso rápido. Durante o programa, as startups recebem orientações de fundadores, empreendedores e investidores experientes.

Há também eventos que tratam de diversos assuntos, como a prática de lançamentos, habilidades de apresentação e aconselhamento jurídico. Ao final dos programas, termina-se com um dia de demonstração (demo day), em que as equipes lançam seus produtos a uma plateia de investidores qualificados.

Coortes ou "turmas" de startups: A cada ciclo, os programas de aceleradoras abrigam coortes ou "turmas" de startups. Muitos gostam desse modelo pois as turmas podem, por exemplo, obter ajuda um do outro para diferentes problemas e, além disso, receber um feedback inicial sobre suas ideais. Ao incentivar as startups a se apoiarem, retira-se um pouco do peso da equipe de gerenciamento da aceleradora, permitindo assim que eles concentrem-se mais em trazer conhecimentos externos (mentoria, investidores, etc.).

Ter a oportunidade de trabalhar junto com outras startups é uma das principais ofertas que o programa oferece para empreendedores. Algumas aceleradoras fornecem um espaço para as startups trabalharem junto em suas instalações, enquanto outros incentivam as equipes a se encontrarem em seus próprios locais para trabalhar. Caso não houver um escritório único para as startups, eles se encontram uma ou duas vezes por semana.

A definição de Miller e Bound [2011] e Barrehag et al. [2012] ajuda a entender bem o conceito do que é uma aceleradora, porém, ela é mais aberta e maleável. Outra definição mais objetiva e sucinta é a de Cohen e Hochberg [2014], p. 4:

"Um programa de prazo fixo, baseado em coortes, incluindo mentoria e componentes educacionais, que culmina em um evento de lançamento público ou dia de demonstração (demo-day)." [Tradução nossa].

De acordo com Cohen e Hochberg [2014], aceleradoras podem atuar com ou sem finalidade lucrativa, e podem variar no montante investido, tamanho da participação acionária tomada, duração do programa de orientação e educação, disponibilidade de espaço de co- 
working (trabalho compartilhado) e no foco vertical da indústria. Algumas aceleradoras são afiliadas às empresas de capital de risco ou grupos de investidores anjo, algumas com corporações e outras com universidades, governos locais ou com organizações não governamentais.

\subsection{Categorias de aceleradoras}

Essa definição da Cohen e Hochberg [2014] implica a existência de vários tipos de aceleradoras, em ramos diferentes e com fins e meios diferentes. De acordo com [DEMPWOLF 2014], há quatro categorias de aceleradoras, sendo corporativas, universitárias sociais e inovadoras, assim como segue.

Aceleradora corporativa: As aceleradoras corporativas são caracterizadas por serem suportadas por empresas. O objetivo dessas aceleradoras é a de tentar complementar os pontos fortes das startups e das empresas grandes [KOHLER 2016].

Startups são fontes de inovação, líderes talentosos e motivados, e novas tecnologias [ANTHONY 2012]. Elas buscam um modelo de negócio escalável e repetível [BLANK e DORF 2012], porém a falta de experiência delas e a alta competitividade as tornam vulneráveis [KOHLER 2016].

As grandes corporações têm a vantagem de já adotarem esse modelo de negócio. Entretanto, o uso desse modelo restringe a inovação, pois o sistema repetível dificulta a busca de novas ideias. Assim, o motivo das empresas grandes montarem suas próprias aceleradoras (corporativas) é para aumentar sua capacidade de inovação por meio da integração de empresas startups [KOHLER 2016].

Aceleradora universitária: Outra espécie de aceleradora que existe no mercado são aquelas afiliadas às universidades. Elas normalmente têm um maior foco no aspecto educativo do programa em vez do potencial lucrativo das startups que são acolhidas, tanto que a maioria não toma uma participação acionária [HOCHBERG 2015]. Da mesma maneira que as outras aceleradoras, elas também providenciam capital semente e fornecem serviços, porém colocam mais ênfase no crescimento das startups (sobrevivência, empregos e renda). [DEMPWOLF, AUER e D'IPPOLITO 2014].

Já para Bliemel et al. [2016], as aceleradoras universitárias continuam com interesse em fazer investimentos futuros após o período de aceleração, mas isso é mais pela questão de melhorar a reputação da instituição através da associação do nome da entidade com uma startup de sucesso do que pelos ganhos financeiros [BLIEMEL et al. 2016].

Aceleradora social: Essas aceleradoras têm como foco ajudar startups que têm como objetivo criar algum produto ou serviço que serve para um fim social. Elas podem, ou não, serem organizações que buscam lucro. Neste caso, elas oferecem sete benefícios principais a seus empreendedores sociais [PANDEY et al. 2017]: Treinamento; Mentoria; Networking com parceiros e clientes; Networking com outros empreendedores; Investimentos diretos via capital semente; Investimentos indiretos através de acesso a investidores; e construindo credibilidade e consciência.

Há maior importância no suporte de startups sociais pelo fato de que elas normalmente têm maior dificuldade de tornarem-se lucrativas no mercado de trabalho, notadamente em virar empresas de alto-impacto [LALL, BOWLES e BAIRD 2013].

Aceleradora inovadora: Este modelo possui todas as características apresentadas na definição de Cohen e Hochberg [2014] (coortes, mentoria, componentes educacionais, demo-day), no entanto, diferencia-se das outras classificações de aceleradoras no ponto de que seu objetivo principal é de obter um lucro significativo através da saída ou IPO (lançamento inicial no mercado de ações) de uma de suas startups [LALL, BOWLES e BAIRD 2013]. Hyytinen, Pajarinen e Rouvinen [2015] notam que startups inovadoras podem 
apresentar, na verdade, uma taxa de sobrevivência mais baixa do que as startups normais, pois elas acabam tomando um risco maior ao introduzirem um produto totalmente novo ao mercado. Isso mostra como aceleradoras inovadoras são organizações que precisam tomar riscos calculados para obterem o sucesso. A figura 1 mostra a taxa de sobrevivência das startups normais e inovadoras. Esse resultado veio de um estudo de 1165 startups da Finlândia, em que se obteve uma diferença de 7-8\% na taxa de sobrevivência de startups inovadoras e não-inovadoras.

Figura 1 - Taxa de sobrevivência de startups normais e startups inovadoras após três anos.

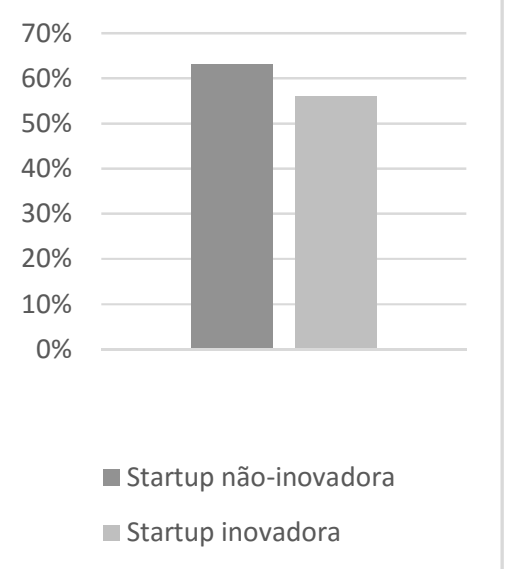

Fonte: adaptado de Hyytinen, Pajarinen e Rouvinen, 2015.

\section{A diferença das aceleradoras para incubadoras e investidores anjo}

Aceleradoras são frequentemente confundidas como incubadoras ou investidores anjo pela mídia, por pesquisadores e por regulamentadores [COHEN e HOCHBERG 2014]. O Quadro 2 resume as principais diferenças entre essas instituições.

Quadro 2 - Resumo das diferenças entre aceleradoras, incubadoras e investidores anjo.

\begin{tabular}{|l|l|l|l|}
\hline & Aceleradoras & Incubadoras & Investidores anjo \\
\hline Duração & 3 meses & $1-5$ anos & Contínuo \\
\hline Coortes & Sim & Não & Não \\
\hline Fodelo de negócio & $\begin{array}{l}\text { Investimento; sem } \\
\text { fins lucrativos }\end{array}$ & $\begin{array}{l}\text { Aluguel; sem fins } \\
\text { lucrativos }\end{array}$ & Investimento \\
\hline $\begin{array}{l}\text { Etapa do } \\
\text { empreendimento }\end{array}$ & $\begin{array}{l}\text { Competitivo, } \\
\text { cíclico seleção-competitivo }\end{array}$ & $\begin{array}{l}\text { Competitivo, } \\
\text { contínuo }\end{array}$ \\
\hline Educação oferecida & Seminários & Ad hoc & Começo \\
\hline $\begin{array}{l}\text { Localização do } \\
\text { empreendimento }\end{array}$ & No local ou tarde & No local & Nenhum \\
\hline Mentoria & $\begin{array}{l}\text { Intenso, individual } \\
\text { e com outros }\end{array}$ & Mínimo, tático & $\begin{array}{l}\text { Quando necessário, } \\
\text { pelo investidor }\end{array}$ \\
\hline
\end{tabular}

Fonte: Traduzido de COHEN e HOCHBERG, 2014.

\subsection{Incubadoras e aceleradoras}

A filosofia do modelo das incubadoras é a de auxiliar novos empreendedores e de protegê-los do hostil ambiente do mercado aberto, de forma a permitir eles crescerem dentro de um espaço seguro [COHEN 2013]. As incubadoras têm foco em desenvolvimento 
econômico, tendo como objetivo abrigar empresas vulneráveis até que elas possam tornaremse independentes [COHEN e HOCHBERG 2014]. As aceleradoras, em contraste, são projetadas para acelerar as interações de novas empresas com o mercado, a fim de ajudar os novos empreendedores a se adaptarem rapidamente. As aceleradoras diferem das incubadoras em cinco dimensões importantes, como duração, coortes ou turmas, seleção e incentivo [COHEN e HOCHBERG 2014], assim como segue.

Duração: Uma característica definidora das aceleradoras é a sua curta duração, que dura em média três meses, enquanto que as empresas que se abrigam nas incubadoras se formam em um período de um a cinco anos. O curto tempo dos programas de aceleração enfoca a atenção dos empreendedores, de forma que eles trabalham a um ritmo insustentável, normalmente trabalhando de segunda a domingo. Participar em um programa desses não necessariamente mantem o empreendimento vivo; em vez disso, pode acelerar o ciclo de vida da empresa, levando a um crescimento brusco ou a uma falência mais rápida. Um fracasso rápido pode ter o benefício de permitir que esses empreendedores sigam outras oportunidades de maior valor [COHEN e HOCHBERG 2014].

Coortes ou "turmas": De certa forma, as startups entram sozinhas em incubadoras, já nas aceleradoras, , elas participam do programa a partir de coortes ou "turmas". Ainda que as startups dentro de uma incubadora são possibilitadas de colaborar entre elas, a experiência de iniciar um programa de aceleração junto com outros empreendedores, como ocorre nas aceleradoras, promove laços e amizades mais forte. [COHEN e HOCHBERG 2014].

Seleção: Outra característica das aceleradoras, devido ao período limitado, é que elas aceitam empreendimentos em lotes, geralmente uma ou duas vezes por ano. As incubadoras, por outro lado, aceitam e formam novas startups de forma contínua. Além disso, o processo de inscrição aberto atrai um amplo número de startups, até mesmo globais. Os fundadores das startups frequentemente se mudam para morar perto ou até mesmo dentro da aceleradora, para que eles possam participar dos programas de aceleração. Dados indicam que principais programas de aceleração aceitam apenas um por cento dos candidatos [COHEN 2013].

Incentivos: Muitas aceleradoras são de propriedade privada e assumem uma participação acionária nos empreendimentos que participam dos seus programas. As incubadoras, por outro lado, são principalmente de propriedade pública, gerenciadas por gerentes e geralmente não possuem seus próprios fundos de investimento, tanto que nos Estados Unidos, 93\% das incubadoras não possuem fins lucrativos e aproximadamente um terço são afiliadas às universidades [COHEN e HOCHBERG 2014]. Como resultado, os diretores das aceleradoras têm um maior incentivo de estarem alinhados com os empreendimentos do seu programa do que os gerentes de incubadoras.

Além disso, alguns dos proprietários das aceleradoras têm uma vasta experiência como empreendedores ou investidores anjo, dando-lhes a experiência necessária para ajudar as startups, auxiliando e guiando em uma infinidade de tarefas, desde desenvolvimento de produto até captação de recursos e contratações. As aceleradoras querem o crescimento das empresas do seu portfólio para que elas possam ter uma saída no mercado, enquanto que as incubadoras preferem um crescimento mais lento, o que atrasa a graduação e prolonga o abrigo da empresa na incubadora [COHEN e HOCHBERG 2014].

Programas educacionais, networking e mentoria: Cohen [2013] afirma que as startups em incubadoras raramente aproveitam os programas de mentoria disponível. Esses programas são normalmente oferecidos por profissionais, como contadores e advogados mediante o pagamento de uma taxa financeira. Nas aceleradoras, por outro lado, mentoria e educação são pontos chaves dos programas de aceleração e muitas vezes são uma das principais razões pelas quais as startups participam. Alguns programas agendam reuniões com até 75 mentores diferentes durante o primeiro mês. 
Os programas incluem seminários educacionais sobre uma ampla gama de temas de empreendedorismo, incluindo economia de unidades, otimização de mecanismos de busca e term sheets. Tais seminários são geralmente oferecidos pelos diretores do programa ou por convidados. Depois da apresentação, eles normalmente fornecem orientação individual para os empreendedores [COHEN 2013].

As oportunidades de mentoria ajudam no desenvolvimento de rede dos empreendedores, tanto que o networking que os fundadores das startups obtêm desses programas é citado como um aspecto importante dos programas de aceleração. Finalmente, os diretores administrativos fornecem orientação ao longo do programa, ajudando os empresários a absorver e aplicar o conhecimento que eles estão obtendo através de reuniões de mentores, seminários e outros meios [COHEN 2013].

\subsection{Investidores anjos e aceleradoras}

As aceleradoras são frequentemente comparadas às incubadoras, contudo, elas na verdade têm mais em comum com investidores anjo. Ambos investem em empreendimentos nascentes, que eles chamam de empresas de portfólio. Como ambos são investidores, eles possuem maior interesse em estarem alinhados com as necessidades das startups, que desejam o crescimento dos seus negócios. Cohen [2013], p. 23, diz:

Os empresários que participaram da minha pesquisa concordam. Embora nenhum deles considerou entrar numa incubadora, quase todos tentaram, ou planejaram, conseguir capital de investidores anjo. Além disso, nenhum dos fundadores de aceleradoras que participaram do estudo tiveram experiências anteriores com incubadoras, mas quase todos eram investidores anjos ativos. $\mathrm{O}$ formato das aceleradoras ajuda a resolver dois problemas para os investidores anjo: a de escolher vencedores e de modificar os caminhos dos empreendimentos [Tradução nossa].

De acordo com Cohen [2013], os investidores anjo diferem das aceleradoras em três pontos principais: duração, seleção e educação/mentoria, assim como segue:

Duração: Por mais que possa parecer um paradoxo, a duração limitada dos programas de aceleração aumenta a influência que os programas têm nas startups de portfólio. Cohen [2013] entrevistou um diretor de aceleração que era um investidor anjo antes de começar sua aceleradora e ele concordava com esse ponto. Ele explicou que, como um anjo, ele estava frustrado pela influência e contato limitado que ele teve com seus clientes, muitas vezes vendo os fundadores somente em reuniões trimestrais. Ele abriu a aceleradora "para melhor estruturar" a maneira pelo qual ele auxiliava as empresas [COHEN 2013].

Como os investimentos são feitos em lotes, os diretores das aceleradoras passam mais tempo com as startups. Contudo, eles trabalham quase que em tempo integral para ajudar um lote de startups por três meses, e depois seguem para o próximo lote. Este contato próximo com as startups aumenta a influência que a direção tem nas empresas do portfólio. A duração limitada dos programas também ajuda a reunir mentores, palestrantes convidados e outros recursos para as startups. Suportes externos, como mentores, podem se comprometer mais facilmente com os empreendimentos, uma vez que o programa é curto [COHEN 2013].

A duração limitada também obriga os empreendedores a se formarem no demo-day. Mais uma vez, a duração estruturada do programa permite aos aceleradores reunir periodicamente grupos de investidores locais, regionais e nacionais. É improvável que os investidores anjo iriam conseguir reunir grupos tão impressionantes ou atrair o mesmo nível de atenção da mídia. Em geral, o tempo comprimido do programa e as normas sociais das aceleradoras incentivam a comunicação frequente entre diretores e startups, e pressionam empreendimentos a aprender e se adaptar rapidamente [COHEN 2013]. 
Seleção: Um dos trabalhos mais difíceis dos investidores anjo é o de selecionar as startups mais promissoras. O programa proposto pelas aceleradoras ajuda os investidores a investirem em empresas, através da combinação dos fundos de vários investidores que acaba se espalhando para o portfólio de startups da aceleradora. Assim, os riscos diminuem e aumenta-se a chance de investir numa startup que começa a crescer demasiadamente [COHEN 2013].

Além disso, é uma prática comum dos investidores aumentarem seus investimentos em alguma startup em destaque. Dessa forma, a aceleradora serve como uma verdadeira opção para os investidores, permitindo que eles aprendam sobre um lote de empreendimentos antes de assumir uma participação financeira maior neles [COHEN 2013].

Educação, mentoria e localização: Outro desafio para os investidores anjo é a de influenciar a direção estratégica das startups. Eles podem ter uma posição na mesa de diretoria e se encontrarem com suas empresas de portfólio periodicamente para orientá-los, mas geralmente não ficam no mesmo local. Em contraste, os diretores de aceleradoras trabalham ao lado de seus empreendimentos participantes e conectá-los com mentores, investidores e empreendedores ativos ou antigos [COHEN 2013].

\section{Conclusão}

Aceleradoras são um fenômeno recente que cressem rapidamente e, às vezes, a pesquisa não consegue andar no mesmo ritmo. Assim, evidencia-se a necessidade de identificar e definir bem as aceleradoras; assim como suas tipologias, para que se possa realizar estudos futuros em uma base sólida. Ainda não se sabe qual o impacto que as aceleradoras terão na sociedade no futuro.

Há autores, como Miller e Bond [2011], que criticam alguns pontos das aceleradoras, uma delas é a possibilidade de uma futura bolha econômica pela supervalorização de startups e outra é que as aceleradoras só servem como um meio de superar as falhas do sistema educacional em vez de serem um ambiente para investidores. Porém, elas conseguem ter um impacto positivo para muitas startups e empreendedores, e mesmo que uma startup acabe falindo, isso até pode acabar sendo benéfico para os fundadores, pois permite irem atrás de outras oportunidades de maior valor. Por mais que a pesquisa esteja um pouco limitada ainda, aceleradoras são organizações que apresentam um bom potencial para o futuro.

\section{Referências}

BLIEMEL, Martin J. et al. The role and performance of accelerators in the Australian startup ecosystem. 2016. Dissertação No. 2016MGMT03 do Department of Industry, Innovation \& Science da UNSW Business School (2016).

KIM, Jin-Hyuk; WAGMAN, Liad. Portfolio size and information disclosure: An analysis of startup accelerators. Journal of Corporate Finance, v. 29, p. 520-534, 2014.

COHEN, Susan. What do accelerators do? Insights from incubators and angels. innovations, v. 8, n. 3-4, p. 19-25, 2013.

HOCHBERG, Yael V. Accelerating entrepreneurs and ecosystems: The seed accelerator model. Innovation Policy and the Economy, v. 16, n. 1, p. 25-51, 2016.

MILLER, Paul; BOUND, Kirsten. The startup factories. NESTA. 2011. 
BARREHAG, Lisa et al. Accelerating success: A study of seed accelerators and their defining characteristics. Bachelor Thesis TEKX04-12-10 Chalmers University, Sweden, 2012.

COHEN, Susan; HOCHBERG, Yael V. Accelerating startups: The seed accelerator phenomenon. 2014.

KOHLER, Thomas. Corporate accelerators: Building bridges between corporations and startups. Business Horizons, v. 59, n. 3, p. 347-357, 2016.

DEMPWOLF, C. Scott; AUER, Jennifer; D'IPPOLITO, Michelle. Innovation accelerators: Defining characteristics among startup assistance organizations. Small Business Administration, 2014.

PANDEY, Sheela et al. The Appeal of Social Accelerators: What do Social Entrepreneurs Value?. Journal of Social Entrepreneurship, v. 8, n. 1, p. 88-109, 2017.

LALL, Saurabh; BOWLES, Lily; BAIRD, Ross. Bridging the "Pioneer Gap": The Role of Accelerators in Launching High-Impact Enterprises. innovations, v. 8, n. 3-4, p. 105-137, 2013.

CERVO, Amdaldo Luiz; BERVIAN, Pedro Alcino. Metodologia da pesquisa: para uso dos estudantes universitários. 1983.

BLANK, Steve; DORF, Bob. The Startup Owner's Manual: The Step-by-Step Guide for Building a Great Company. Pescadero, CA: K\&S Ranch. Inc. Publishers, 2012.

ANTHONY, S. The new corporate garage (pp. 44-53). September: Harvard Business Review, 2012.

HYYTINEN, Ari; PAJARINEN, Mika; ROUVINEN, Petri. Does innovativeness reduce startup survival rates? Journal of Business Venturing, v. 30, n. 4, p. 564-581, 2015. 